\title{
Fruit and vegetable consumption in relation to hepatocellular carcinoma in a multi-centre, European cohort study
}

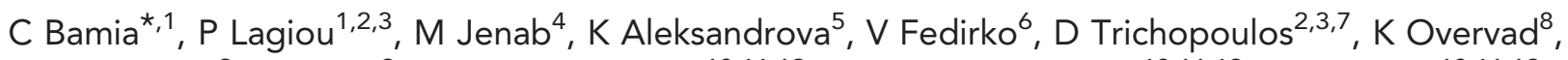
A Tjønneland ${ }^{9}$, A Olsen 9 , F Clavel-Chapelon ${ }^{10,11,12}$, M-C Boutron-Ruault ${ }^{10,11,12}$, M Kvaskoff ${ }^{10,11,12,}$ V A Katzke ${ }^{13}, \mathrm{~T} \mathrm{Kühn}^{13}$, $\mathrm{H} \mathrm{Boeing}^{5}$, U Nöthlings ${ }^{14}$, D Palli ${ }^{15}, \mathrm{~S}$ Sieri ${ }^{16}$, S Panico ${ }^{17}$, R Tumino ${ }^{18}$, A Naccarati $^{19}$, HB(as) Bueno-de-Mesquita 20,21,22,23, P H M Peeters ${ }^{23,24}$, E Weiderpass ${ }^{25,26,27,28}$, G Skeie ${ }^{25}$, J R Quirós ${ }^{29}$, A Agudo $^{30}$, M-D Chirlaque ${ }^{31,32}$, M-J Sanchez ${ }^{32,33}$, E Ardanaz ${ }^{32,34}$, M Dorronsoro ${ }^{35,36}$, U Ericson ${ }^{37}$, L M Nilsson ${ }^{38,39}, \mathrm{M} \mathrm{Wennberg}^{38}$, K-T Khaw ${ }^{40}$, N Wareham ${ }^{40,41}, \mathrm{~T} \mathrm{~J} \mathrm{Key}^{42}$, R C Travis ${ }^{42}, \mathrm{P}$ Ferrari ${ }^{4}, \mathrm{M} \mathrm{Stepien}^{4}$, T Duarte-Salles ${ }^{4}, \mathrm{~T} \mathrm{Norat}^{23}, \mathrm{~N}$ Murphy ${ }^{23}, \mathrm{E} \mathrm{Riboli}^{23}$ and A Trichopoulou ${ }^{1,7}$

${ }^{1}$ Department of Hygiene, Epidemiology and Medical Statistics, University of Athens Medical School, Athens 115 27, Greece; ${ }^{2}$ Department of Epidemiology, Harvard School of Public Health, 02115 Boston, MA, USA; ${ }^{3}$ Bureau of Epidemiologic Research, Academy of Athens, Athens 106 79, Greece; ${ }^{4}$ International Agency for Research on Cancer (IARC-WHO), 69372 Lyon, France; ${ }^{5}$ Department of Epidemiology, German Institute of Human Nutrition Potsdam-Rehbruecke, Nuthetal 14558, Germany; ${ }^{6}$ Department of Epidemiology, Rollins School of Public Health, Winship Cancer Institute, Emory University, Atlanta 30322, GA, USA; ${ }^{7}$ Hellenic Health Foundation, Athens 115 27, Greece; ${ }^{8}$ Department of Public Health, Section for Epidemiology, Aarhus University, DK-8000 Aarhus C, Denmark; ${ }^{9}$ Danish Cancer Society Research Center, DK-2100 Copenhagen, Denmark; ${ }^{10}$ Inserm, Centre for Research in Epidemiology and Population Health (CESP), U1018, Nutrition, Hormones and Women's Health Team, Villejuif, F-94805 Paris, France; ${ }^{11}$ Paris South University, UMRS 1018, Villejuif, F-94805 Paris, France; ${ }^{12}$ IGR, Villejuif, F-94805 Paris, France; ${ }^{13}$ Division of Cancer Epidemiology, German Cancer Research Center (DKFZ), 69120 Heidelberg, Germany; ${ }^{14}$ Department of Nutrition and Food Sciences, University of Bonn, 53111 Bonn, Germany; ${ }^{15}$ Molecular and Nutritional Epidemiology Unit, Cancer Research and Prevention Institute-ISPO, 50139 Florence, Italy; ${ }^{16}$ Epidemiology and Prevention Unit, Fondazione IRCCS Istituto Nazionale dei Tumori, 20133 Milan, Italy; ${ }^{17}$ Dipartimento di Medicina Clinica e Chirurgia Federico II University, 80131 Naples, Italy; ${ }^{18}$ Cancer Registry and Histopathology Unit, 'Civic-M.P. Arezzo' Hospital, ASP 97100 Ragusa, Italy; ${ }^{19}$ HuGeF-Human Genetics Foundation-Torino Molecular and Genetic Epidemiology Unit, 10126 Torino, Italy; ${ }^{20}$ Department for Determinants of Chronic Diseases (DCD), National Institute for Public Health and the Environment (RIVM), 3720 BA Bilthoven, The Netherlands; ${ }^{21}$ Department of Gastroenterology and Hepatology, University Medical Centre Utrecht, 3508 GA Utrecht, The Netherlands; ${ }^{22}$ Department of Social and Preventive Medicine, Faculty of Medicine, University of Malaya, 50603 Kuala Lumpur, Malaysia; ${ }^{23}$ Department of Epidemiology and Biostatistics, School of Public Health, Faculty of Medicine, Imperial College, W2 1NY UK London, UK; ${ }^{24}$ Julius Center for Health Sciences and Primary Care, University Medical Center Utrecht, 3508 GA Utrecht, The Netherlands; ${ }^{25}$ Department of Community Medicine, Faculty of Health Sciences, UiT The Arctic University of Norway, N-9037 Tromsø, Norway; ${ }^{26}$ Cancer Registry of Norway, NO-0304 Oslo, Norway; ${ }^{27}$ Department of Medical Epidemiology and Biostatistics, Karolinska Institutet, SE-171 Stockholm, Sweden; ${ }^{28}$ Department of Genetic Epidemiology, Folkhälsan Research Center, 00250 Helsinki, Finland; ${ }^{29}$ Public Health Directorate, CP 33006 Oviedo, Asturias, Spain; ${ }^{30}$ Unit of Nutrition, Environment and Cancer, Cancer Epidemiology Research Program, Catalan Institute of Oncology (ICO), 08908 Barcelona, Spain; ${ }^{31}$ Epidemiology Department, Murcia Regional Health Council, E-30008 Murcia, Spain; ${ }^{32}$ CIBER Epidemiology and Public Health CIBERESP, 28029 Madrid, Spain; ${ }^{33}$ Escuela Andaluza de Salud Pública, Instituto de Investigación Biosanitaria ibs, GRANADA, Hospitales 
Universitarios de Granada/Universidad de Granada, 18080 Granada, Spain; ${ }^{34}$ Navarre Public Health Institute, 31003 Pamplona, Spain; ${ }^{35}$ Basque Regional Health Department, Public Health Direction, 4-20013 Donostia, San Sebastian, Spain; ${ }^{36}$ Biodonostia Research Institute CIBER Epidemiology and Public Health CIBERESP, s/n 20014 San Sebastian, Spain; ${ }^{37}$ Diabetes and Cardiovascular disease, Genetic Epidemiology Department of Clinical Sciences in Malmö Lund University, SE-205 92 Malmo, Sweden; ${ }^{38}$ Department of Nutritional Research, Public Health and Clinical Medicine, Umeå University, SE-901 85 Umeå, Sweden; ${ }^{39}$ Arcum, Arctic Research Centre at Umeå University, SE-901 85 Umeå, Sweden; ${ }^{40}$ University of Cambridge, CB2 0SR Cambridge, UK; ${ }^{41}$ MRC Epidemiology Unit, CB2 000 Cambridge, UK and ${ }^{42}$ Cancer Epidemiology Unit, Nuffield Department of Population Health, University of Oxford, OX3 7LF Oxford, UK

Background: Vegetable and/or fruit intakes in association with hepatocellular carcinoma (HCC) risk have been investigated in case-control studies conducted in specific European countries and cohort studies conducted in Asia, with inconclusive results. No multi-centre European cohort has investigated the indicated associations.

Methods: In 486799 men/women from the European Prospective Investigation into Cancer and nutrition, we identified 201 HCC cases after 11 years median follow-up. We calculated adjusted hazard ratios (HRs) for HCC incidence for sex-specific quintiles and per $100 \mathrm{~g} \mathrm{~d}^{-1}$ increments of vegetable/fruit intakes.

Results: Higher vegetable intake was associated with a statistically significant, monotonic reduction of $\mathrm{HCC}$ risk: $\mathrm{HR}\left(100 \mathrm{gd}^{-1}\right.$ increment): $0.83 ; 95 \% \mathrm{Cl}$ : 0.71-0.98. This association was consistent in sensitivity analyses with no apparent heterogeneity across strata of HCC risk factors. Fruit intake was not associated with HCC incidence: HR (100 $\mathrm{g} \mathrm{d}^{-1}$ increment): 1.01; 95\% Cl: 0.92-1.11.

Conclusions: Vegetable, but not fruit, intake is associated with lower HCC risk with no evidence for heterogeneity of this association in strata of important HCC risk factors. Mechanistic studies should clarify pathways underlying this association. Given that HCC prognosis is poor and that vegetables are practically universally accessible, our results may be important, especially for those at high risk for the disease.

Hepatocellular carcinoma (HCC) is a leading cause of cancer mortality worldwide, resulting in more than 600000 deaths annually (Ferlay et al, 2013). Apart from the well-established risk factors of chronic infection with hepatitis B (HBV) and hepatitis $\mathrm{C}$ (HCV), several modifiable risk factors for HCC have been identified (Trichopoulos et al, 2011) but only alcohol (International Agency for Research on Cancer, 1988), obesity (Schlesinger et al, 2013) and aflatoxin (International Agency for Research on Cancer, 2002) have been documented as diet related. The role of other dietary exposures is still under investigation (Chuang et al, 2009).

Vegetables and fruit are practically universally accessible, and higher intakes have been associated with lower cancer incidence, overall and by several sites (Vainio and Weiderpass, 2006; Soerjomataram et al, 2010), although their role in cancer prevention is still inconclusive (World Cancer Research Fund/ American Institute for Cancer Research, 2007). Regarding the association of vegetables and fruit with HCC, studies are scarce with conflicting results. Higher intakes of vegetables and a vegetable-based dietary pattern have been associated with lower HCC risk, in case-control studies in Italy (La Vecchia et al, 1988; Negri et al, 1991; Braga et al, 1997; Talamini et al, 2006) and Serbia (Kanazir et al, 2010) and cohort studies conducted exclusively in Asia (Yu et al, 1995; Sauvaget et al, 2003; Kurozawa et al, 2004; Pham et al, 2006; Kurahashi et al, 2009; Zhang et al, 2013), although in a case-control study in Greece a null association between vegetables and HCC risk was reported (Kuper et al, 2000). The association of fruit intake with HCC risk has been investigated in fewer studies and was reported as inverse in Italian case-control studies (La Vecchia et al, 1988; Negri et al, 1991; Braga et al, 1997; Talamini et al, 2006), as positive in a cohort study in Japan (Kurahashi et al, 2009) and as null in a cohort study in China (Zhang et al, 2013). Owing to these conflicted results, in a major review, the evidence regarding the indicated associations was considered inconclusive (World Cancer Research Fund/American Institute for Cancer Research, 2007).
The earlier studies differed by location and background of HCC rates (higher in Asian as compared with European populations), patterns of vegetable/fruit consumption (different in eastern compared with western populations), as well as, in the extent of adjustment for established HCC risk factors, and in the assessment and quantification of vegetable/fruit intakes. Moreover, in most studies, vegetables and fruit were considered independently of each other, although they may act as mutual confounders in their individual associations with HCC risk.

We investigated the associations of vegetable and fruit intakes with HCC risk, in the context of the European Prospective Investigation into Cancer and nutrition (EPIC). This is the first multinational, European-based prospective cohort study undertaken on this topic.

\section{MATERIALS AND METHODS}

Participants. EPIC investigates the role of dietary and lifestyle, as well as, biological factors in the aetiology of cancer and other chronic diseases. The EPIC study has been previously described in detail (Riboli et al, 2002). More than 500000 apparently healthy men and women, aged 25-70 years, were recruited between 1992 and 2000 in 23 centres from 10 European countries (Denmark, France, Germany, Greece, Italy, the Netherlands, Norway, Spain, Sweden and United Kingdom). The participants are from the general population, except for France (women-members of health insurance plans), Utrecht and Florence (women-breast cancer screening), Naples and Norway (women only), the Oxford cohort (which includes a large proportion of vegetarian volunteers) and subsamples of the Italian and Spanish cohorts (mainly members of blood donor associations).

The study was approved by the Ethical Review Board of the International Agency for Research on Cancer, and by the local Ethics Committees in the participating centres. Participants gave 
informed consent before enrolment. Procedures were in line with the Helsinki declaration.

Assessment of diet. Dietary intakes over the previous year were assessed at enrolment with validated centre-specific questionnaires, or food records (Margetts et al, 1997), which enquired also about vegetable and fruit consumption (Slimani et al, 2002). On the basis of this information, daily intake of vegetables and fruit was estimated in grams (Agudo et al, 2002). Legumes and potatoes, as well as vegetable juices are not included in the vegetables food group. Fruit juices, nuts and seeds are not included in the fruit food group. Total energy intake was calculated through the EPIC nutrient database (Slimani et al, 2007).

Calibration of the dietary data. A second dietary measurement was taken from an 8\% random sample of the cohort (36994 participants) using a detailed computerised 24-h dietary recall (24HR) method (Slimani et al, 2002) to calibrate dietary measurements of foods and food groups including vegetables and fruit intakes across countries (Rosner and Gore, 2001; Ferrari et al, 2004).

Assessment of lifestyle, antropometry and medical history. At enrolment, sociodemographic, lifestyle and medical history data were also recorded through standardised questionnaires. Weight, height and waist/hip circumferences were measured for most participants, whereas for a small fraction only self-reported weight and height were available.

Follow-up of study population and case ascertainment. Incident HCC cases (first primary) and vital status were ascertained through record linkage with cancer and death registries in most centres (Riboli et al, 2002). In France, Germany and Greece, an ascertainment was done with a combination of methods including health insurance records, pathology registries and active follow-up through mailed questionnaires/telephone interviews (Riboli et al, 2002). Incident cancers were subsequently verified through medical records, pathology reports and discharge diagnoses. Cancer incidence was coded according to the International Classification of Diseases-Oncology-2. HCC was defined as C22.0.

Censoring dates for cancer incidence for centres using registry data ranged from December 2004 (Asturias (Spain)) to December 2008 (Turin (Italy), Sweden and Norway). For centres using active follow-up, last contact ranged from July 2005 (France) to June 2010 (Heidelberg (Germany)).

From the initial 521330 EPIC participants, 23818 with prevalent cancer, 4383 with insufficient follow-up (e.g., lost from follow-up immediately after recruitment), 78 cases with metastatic cancer or ineligible information on histology, 6192 with no dietary and 60 with no lifestyle questionnaires were excluded. Eventually, 486799 participants including 201 HCC incident cases were analysed.

Nested case-control study subset. A nested case-control study, using EPIC data as of 2006, including 125 HCC cases and 250 matched controls with available biological samples was conducted. For these subjects, additional laboratory measurements were undertaken regarding established risk factors for HCC (notably serum levels of hepatitis B surface antigen (HBsAg) and antibodies to HCV), which are not available for the whole EPIC cohort. Serum levels of HBsAg and antibodies to HCV (anti-HCV) were determined at the Centre de Biologie République laboratory in Lyon, France. Design and methods of this study have been described elsewhere (Trichopoulos et al, 2011). Controls were selected from those alive and free of cancer (except for nonmelanoma skin cancer) at the time of diagnosis of the case. Matching criteria included study centre, sex, age at the time of blood collection, date and time of day of blood collection. Women were additionally matched by menopausal status and by use of exogenous hormones.
Statistical analysis. The associations of vegetable intake and fruit intake with HCC risk were investigated through Cox proportional hazard regression. The underlying time variable was age at exit defined as the age of: HCC diagnosis (case); diagnosis of any other incident cancer (censored); death for participants who died without cancer (censored); last follow-up for those alive and with no cancer (censored). Age at enrolment was the entry time. All models were stratified by recruitment age (1-year intervals) and EPIC centre.

Vegetable intake and fruit intake were considered in sex-specific quintiles (categorically, by assigning 0-4 to quintiles Q1-Q5), and as continuous (in $100 \mathrm{gd}^{-1}$ increments). The associations of vegetable and fruit intakes with HCC risk were evaluated: (a) by considering vegetable intake and fruit intake separately, (b) by using the sum of vegetables and fruit intakes as a common dietary variable, and (c) by mutually adjusting for vegetable and fruit intakes. Deviations from log linearity of the estimated associations between fruit and vegetable intakes and HCC risk were assessed by comparing models including vegetable and fruit intakes as continuous, with models including both dietary exposures as categorical, using the likelihood ratio test (LRtest).

In all analyses, potential confounders were: sex, self-reported diabetes (categorically: no, yes, unknown), education (categorically: no formal/primary school, technical/secondary school, university/ longer, unknown), physical activity (categorically: inactive/moderately inactive, moderately active/active, unknown), smoking (categorically: never, former smoker, current smoker, unknown), ethanol intake (categorically: low: men $<10 \mathrm{gd}^{-1}$, women $<5 \mathrm{gd}^{-1}$; moderate: men $10-<40 \mathrm{gd}^{-1}$, women $5-<20 \mathrm{gd}^{-1}$; high: men $\geqslant 40 \mathrm{gd}^{-1}$, women $\geqslant 20 \mathrm{gd}^{-1}$ ), body mass index (categorically: $\leqslant 25 \mathrm{~kg} \mathrm{~m}^{-2},>25$ to $<30 \mathrm{~kg} \mathrm{~m}^{-2}, \geqslant 30 \mathrm{~kg} \mathrm{~m}^{-2}$ ) and energy intake (continuously). In order to minimise residual confounding by smoking/ethanol intake, we further used more detailed variables (but with more missing values), accounting for duration and intensity of smoking and for lifetime alcohol drinking. We also further included in the Cox models meat and coffee intakes to account for residual confounding by these variables.

In the analysis of the nested case-control study, the associations of vegetables and fruit were evaluated through conditional logistic regression adjusting also for $\mathrm{HBV} / \mathrm{HCV}$ status (positive/negative), as well as, for self-reported diabetes, body mass index, smoking status, ethanol intake, education and energy intake, as previously indicated.

Calibration of the estimated associations. We further recalculated the log linear associations between vegetable intake and fruit intake with HCC risk after performing linear calibration using data from the second dietary measurement (24HR) study (Rosner and Gore, 2001; Ferrari et al, 2004). In brief, the $24 \mathrm{HR}$ data were regressed on the intakes of vegetables and fruits, as estimated from the main dietary questionnaire including in the regression models the same potential confounders as in the above-indicated survival models, and further weighted by day of the week and season of the year during which the $24 \mathrm{HR}$ was collected. The coefficients from the regression models were used to obtain individual predicted (calibrated) values of vegetable and fruit intakes for all participants. Cox regression models, as specified above, using calibrated vegetable intake and fruit intake as continuous (per $100 \mathrm{~g} \mathrm{~d}^{-1}$ increment) were then run in order to obtain the calibrated hazard ratios (HRs). The s.e. of the estimated coefficients (i.e., log of the HRs) were calculated with bootstrap sampling (100 iterations) in the calibration and survival models consecutively and were used to estimate the calibrated 95\% CI associated with the calibrated HR (Rosner and Gore, 2001). 
Sensitivity analyses. We performed sensitivity analyses by recalculating the HRs after excluding subjects with missing values on any of the potentially confounding variables that were included in the multivariable models (in order to investigate any influence that missing data on covariates have on the estimated associations). We also restricted the analysis to the 169 histologically confirmed HCC cases. We repeated our analyses after excluding 9596 subjects (10 cases) in the top/bottom $1 \%$ of the energy intake distribution (as calculated from the dietary questionnaires and divided by the estimated energy requirement). Finally, we re-estimated the associations between vegetables/fruit intake and HCC risk after excluding the initial 2 years of follow-up, in order to minimise possible effects of pre-existing disease on vegetable and fruit intakes.

Assessing modification of estimated associations across subgroups. Furthermore, we investigated whether the estimated associations differed by sex, diabetes, smoking, ethanol intake and body mass index, by introducing interaction terms between quintiles of vegetable/fruit intakes (ordered) and each of the indicated variables (categorically). The evidence of statistically significant interactions in the multiplicative scale was tested with the LRtest comparing nested models (i.e., with and without the interaction term(s)).

$P<0.05$ was considered statistically significant. Analyses were performed using STATA (Stata Corporation: Stata statistical software, release 11. College Station, TX, USA: Stata Corporation; 2009). Calibration models were run using SAS version 9.3 (SAS Institute, Cary, NC, USA).

\section{RESULTS}

After a median follow-up of 11 years, 1622408 and 3744060 person-years were accrued from the 145039 (30\%) men and $341760(70 \%)$ women of the study population, and 133 men and 68 women were diagnosed with HCC.

Table 1 presents the distribution of 486799 study participants according to sex-specific quintiles of vegetable intake, country of origin and baseline characteristics. Overall median vegetable consumption was $151 \mathrm{~g} \mathrm{~d}^{-1}$ among men and $185 \mathrm{~g} \mathrm{~d}^{-1}$ among women; vegetable intake varied across countries, with the Greeks consuming the highest quantities. Participants with higher vegetable intakes were slightly older and had higher energy intake. Those more educated tended to consume higher quantities of vegetables compared with those less educated as did the never/ former smokers compared with current smokers and the moderate/high ethanol consumers compared with no- or lowethanol consumers. Participants with higher body mass index and/ or of lower physical activity consumed higher amounts of vegetables than people with lower body mass index and/or higher physical activity, respectively. Finally, the EPIC subjects who reported to have had diabetes at enrolment, tended to consume more vegetables than the vast majority who did not report diabetes at enrolment.

In Table 2, corresponding distributions as in Table 1 are presented by categories of fruit intake. Median fruit intakes were $156 \mathrm{gd}^{-1}$ for men and $209 \mathrm{gd}^{-1}$ for women. Distribution of participants across categories of fruit intake also varied across countries, with the highest intakes consumed in Greece and Italy. Similarly to vegetable intakes, higher fruit intakes were consumed more frequently: from the slightly older and those with higher energy intakes; from the never/former compared with current smokers; from those with higher compared with lower body mass index; by those with lower compared with higher level of physical activity; and by those who reported to have had diabetes compared with those who did not report diabetes at enrolment. The more educated, however, tended to consume lower quantities of fruit compared with those less educated as did the moderate/high ethanol consumers compared with no- or low-ethanol consumers.

Table 3 shows HRs for HCC incidence by quintiles of vegetable/ fruit intakes, separately (models 1 and 2) and after mutual adjustment (model 3). Higher vegetable intake was associated with a monotonic reduction in HCC risk in all models, which reached statistical significance when the association between vegetables and HCC risk was assumed log linear ( $P$-values associated with $100 \mathrm{~g} \mathrm{~d}^{-1}$ increment in vegetable intake for models 1,2 and 3, respectively, were $0.028,0.027$ and 0.027 ). Fruit intake, however, was not associated with HCC incidence. No appreciable change in the estimated associations was apparent when duration/intensity of smoking and lifetime alcohol drinking were used as confounders instead of smoking status and ethanol intake at recruitment, or, when meat and coffee intakes were additionally adjusted for.

When the association of vegetable and fruit intakes with HCC risk was assessed by considering the sum of the individual vegetable and fruit intakes, trend results from the fully adjusted HR were, as expected, inverse but not statistically significant (HR for $200 \mathrm{~g}$ increment in vegetable and fruit intake 0.90 ; $95 \% \mathrm{CI}: 0.78-$ 1.05). There was no statistical evidence indicating that log linear models (i.e., using vegetable and fruit intakes as continuous) were of inferior fit as compared with models with no assumption for the type of association of these dietary exposures with HCC risk (i.e., using vegetable and fruit intakes in quintiles, categorically): LRtest $_{\text {vegetables }}>0.999$, LRtest $_{\text {fruit }}=0.464$.

Linear calibration enhanced the strength of the indicated associations but also increased the uncertainty of the estimates: HR for $100 \mathrm{~g} \mathrm{~d}^{-1}$ increment in vegetable intake: 0.72 ; 95\% CI: $0.49-1.07$; HR for $100 \mathrm{~g} \mathrm{~d}^{-1}$ increment in fruit intake: 0.98; 95\% CI: 0.83-1.15.

Sensitivity analyses. Results from sensitivity analyses (using model 3) revealed similar patterns of associations for vegetable intakes with HCC risk, but with larger confidence intervals associated with the respective estimates. More specifically, the HRs associated with $100 \mathrm{~g}$ increment in vegetable intake were: $0.83 ; 95 \%$ CI: $0.70-0.99$ ( $P$-value 0.033$)$ when subjects without missing values were studied (187 HCC cases/413 666 participants); 0.87; 95\% CI: 0.74-1.02 ( $P$-value 0.094) when 9596 subjects ( 10 HCC cases) in the top/bottom $1 \%$ of the energy intake distribution were excluded; 0.90; 95\% CI: 0.76-1.06 ( $P$-value 0.210$)$ when analysis was restricted to the 169 histologically confirmed HCC, and; 0.85; 95\% CI: 0.71-1.01 ( $P$-value 0.066$)$ when the first 2 years of followup were excluded (173 HCC cases/478 436 participants analysed).

The association of fruit intake with HCC risk was essentially null in all sensitivity analyses.

Examination of effect-modifications. In Table 4, evaluation of possible interactions in the multiplicative scale between vegetable and fruit intakes on one hand (per $100 \mathrm{~g} \mathrm{~d}^{-1}$ increments) and certain covariates (in categories as shown in Table 4) on the other hand, among participants without missing data (187 HCC cases/ 413666 participants) are shown. The inverse association of vegetable intake with HCC risk was manifested mainly among males, among non-diabetics, among ever smokers, among subjects with moderate/high alcohol intakes and among overweight/obese subjects; nevertheless, the respective interaction terms were far from being statistically significant. The association of fruit intake with HCC risk was in general null in subgroups shown in Table 4, and the respective interaction terms were also far from being statistically significant.

In the analysis of the nested case-control study, the unadjusted, as well as the adjusted for $\mathrm{HBV} / \mathrm{HCV}$ positivity status associations of vegetables and fruit with HCC risk were in the same direction as in the cohort study but not statistically significant: per $100 \mathrm{~g} \mathrm{~d}^{-1}$ increment the adjusted odds ratios (ORs) were: $\mathrm{OR}_{\text {vegetables }} 0.92$; 95\% CI: 0.66-1.28; OR fruit 0.86; 95\% CI: 0.67-1.10 (model with 
Table 1. Distribution of baseline characteristics of study participants by quintiles ${ }^{a}$ of vegetable intake

\begin{tabular}{|c|c|c|c|c|c|}
\hline & \multicolumn{5}{|c|}{ Quintiles of vegetable intake $\left(\mathrm{g} \mathrm{d}^{-1}\right)$} \\
\hline & Q1 & Q2 & Q3 & Q4 & Q5 \\
\hline Median (range): males & $56.1(0-82.5)$ & $104.4(82.5-126.2)$ & $151.2(126.2-182.1)$ & $222.0(182.1-282.0)$ & $387.7(>282.0)$ \\
\hline Median (range): females & $76.5(0-104.9)$ & $129.5(104.9-155.7)$ & $185.1(155.7-219.2)$ & $260.7(219.21-315.70)$ & $403.7(>315.7)$ \\
\hline \multicolumn{6}{|l|}{ Country $^{\mathrm{b}}(\%)$} \\
\hline France & 5.8 & 10.3 & 19.1 & 30.3 & 34.5 \\
\hline Italy & 21.5 & 23.3 & 24.6 & 20.9 & 9.7 \\
\hline Spain & 12.5 & 13.5 & 18.5 & 25.3 & 30.3 \\
\hline United Kingdom & 4.7 & 10.7 & 20.9 & 31.7 & 32.0 \\
\hline Netherlands & 28.0 & 40.4 & 23.8 & 7.2 & 0.6 \\
\hline Greece & 0.5 & 1.2 & 3.5 & 14.1 & 80.6 \\
\hline Germany & 33.7 & 36.7 & 21.0 & 7.1 & 1.5 \\
\hline Sweden & 46.0 & 21.4 & 16.9 & 10.9 & 4.7 \\
\hline Denmark & 20.7 & 20.5 & 24.3 & 23.4 & 11.2 \\
\hline Norway & 36.7 & 28.8 & 20.2 & 10.7 & 3.6 \\
\hline Age (years): mean (s.d.) & $50(10)$ & $51(10)$ & $51(10)$ & $52(10)$ & $52(11)$ \\
\hline \multicolumn{6}{|c|}{ Self-reported diabetes mellitus ${ }^{\mathrm{b}}(\%)$} \\
\hline No & 19.9 & 20.0 & 20.0 & 20.0 & 20.0 \\
\hline Yes & 14.8 & 17.1 & 17.9 & 20.2 & 30.0 \\
\hline \multicolumn{6}{|l|}{ Educational level ${ }^{\mathrm{b}}(\%)$} \\
\hline None/primary & 23.6 & 19.3 & 18.4 & 17.9 & 20.9 \\
\hline Technical/professional/secondary & 21.8 & 21.8 & 20.6 & 19.1 & 16.7 \\
\hline University degree/longer & 14.3 & 18.9 & 21.1 & 23.0 & 22.7 \\
\hline \multicolumn{6}{|l|}{ Smoking $^{\mathrm{b}}(\%)$} \\
\hline Never & 18.4 & 18.8 & 19.9 & 21.2 & 21.7 \\
\hline Former & 18.6 & 20.8 & 20.7 & 20.5 & 19.4 \\
\hline Current & 25.7 & 22.3 & 19.5 & 16.5 & 16.0 \\
\hline \multicolumn{6}{|l|}{ Ethanol intake $\left(\mathrm{g} \mathrm{d}^{-1}\right)^{\mathrm{b}}(\%)$} \\
\hline Low $^{c}$ & 23.7 & 19.8 & 18.6 & 18.2 & 19.8 \\
\hline Moderate $^{c}$ & 16.0 & 20.2 & 21.5 & 22.0 & 20.3 \\
\hline $\mathrm{High}^{c}$ & 16.1 & 20.3 & 21.6 & 21.9 & 20.1 \\
\hline \multicolumn{6}{|l|}{ Body mass index ${ }^{b}\left(\mathrm{~kg} \mathrm{~m}^{-2}\right)(\%)$} \\
\hline$\leqslant 25$ & 20.0 & 20.0 & 20.4 & 20.8 & 18.8 \\
\hline$>25-<30$ & 20.3 & 20.5 & 20.0 & 19.3 & 20.0 \\
\hline$\geqslant 30$ & 19.1 & 18.9 & 18.5 & 18.7 & 24.8 \\
\hline \multicolumn{6}{|l|}{ Physical activity index ${ }^{b}(\%)$} \\
\hline Moderately inactive $^{d}$ & 18.9 & 18.3 & 19.7 & 21.0 & 22.2 \\
\hline Moderately active ${ }^{d}$ & 18.2 & 20.2 & 20.3 & 20.7 & 20.7 \\
\hline Energy intake (kcal d ${ }^{-1}$ ): mean (s.d.) & $1837.5(626.7)$ & $2011.4(621.8)$ & $2103.1(646.9)$ & $2182.0(672.5)$ & $2290.3(731.4)$ \\
\hline Total (number) & 97359 & 97359 & 97361 & 97360 & 97360 \\
\hline \multicolumn{6}{|c|}{ 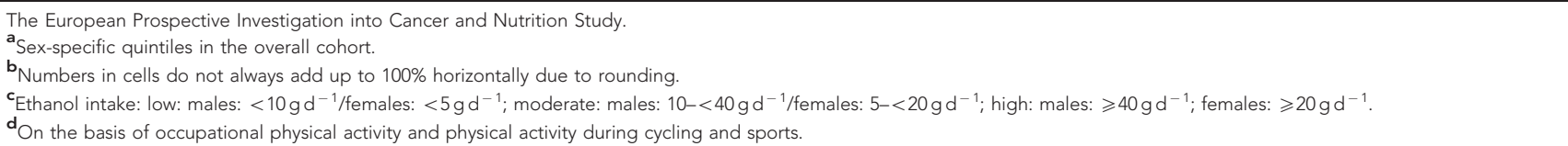 } \\
\hline
\end{tabular}

both vegetables and fruit included). No evidence for effect modification of the impact of vegetable and fruit intakes on $\mathrm{HCC}$ risk according to $\mathrm{HBV} / \mathrm{HCV}$ status was observed when the respective interaction terms were included in the model $(P$ interaction of $\mathrm{HBV} / \mathrm{HCV}$ status: by vegetable intake 0.897 ; by fruit intake 0.349).

\section{DISCUSSION}

In this multi-centre European cohort, we observed a monotonic significant inverse association of intakes of vegetables with HCC incidence, notwithstanding the modest size of HCC cases. Compared with those with minimal consumption of vegetables, and adjusted also for fruit intake, those in the highest quintile of vegetable intake had a lower HCC risk by about $42 \%$, whereas $100 \mathrm{~g} \mathrm{~d}^{-1}$ increment in vegetable intake was associated with a $17 \%$ decrease in HCC incidence ( $P$-value 0.027$)$. For fruit, no association with HCC risk was evident in any of the analyses undertaken. This is the first prospective cohort study in a multicentre western population that has investigated the association of vegetable and fruit intakes with HCC risk.

Our results are in line with those reported in most (La Vecchia et al, 1988; Negri et al, 1991; Braga et al, 1997; Talamini et al, 2006; Kanazir et al, 2010) but not all (Kuper et al, 2000), case-control European studies and cohort Asian studies (Yu et al, 1995; Sauvaget et al, 2003; Kurozawa et al, 2004; Pham et al, 2006; Kurahashi et al, 2009; Zhang et al, 2013), with respect to the inverse association of vegetable consumption with HCC risk; however, the indicated inverse associations were not as strong in our study as in the previous case-control European investigations. The strength of the associations estimated in our study were close to the ones reported from the Asian cohort studies (Sauvaget et al, 2003; Kurahashi et al, 2009), in which associations were quantified in a similar manner to ours (e.g., comparing percentiles of vegetable intake). 
Table 2. Distribution of baseline characteristics of study participants by quintiles ${ }^{a}$ of fruit intake

\begin{tabular}{|c|c|c|c|c|c|}
\hline & \multicolumn{5}{|c|}{ Quintiles of fruit intake $\left(\mathrm{g} \mathrm{d}^{-1}\right)$} \\
\hline & Q1 & Q2 & Q3 & Q4 & Q5 \\
\hline Median (range): males & $35.7(0.0-66.2)$ & $95.2(66.2-123.3)$ & $156.1(123.3-197.3)$ & 250.0 (197.3-320.5 & $435.8(>320.5)$ \\
\hline Median (range): females & $62.0(0.00-101.7)$ & $134.9(101.7-171.0)$ & 208.5 (171.0-249.0) & $295.8(249.0-356.4)$ & $461.1(>356.4)$ \\
\hline \multicolumn{6}{|l|}{ Country $^{\mathrm{b}}(\%)$} \\
\hline $\begin{array}{l}\text { France } \\
\text { Italy } \\
\text { Spain } \\
\text { United Kingdom } \\
\text { Netherlands } \\
\text { Greece } \\
\text { Germany } \\
\text { Sweden } \\
\text { Denmark } \\
\text { Norway }\end{array}$ & $\begin{array}{r}14.8 \\
5.3 \\
13.7 \\
15.7 \\
21.5 \\
3.7 \\
34.1 \\
25.0 \\
28.3 \\
36.3\end{array}$ & $\begin{array}{r}18.1 \\
9.3 \\
10.0 \\
18.8 \\
24.4 \\
6.9 \\
31.2 \\
25.4 \\
23.2 \\
28.3\end{array}$ & $\begin{array}{l}21.0 \\
17.6 \\
13.7 \\
22.7 \\
22.6 \\
13.6 \\
19.9 \\
22.9 \\
21.5 \\
18.3\end{array}$ & $\begin{array}{l}25.3 \\
27.5 \\
25.1 \\
21.8 \\
18.5 \\
28.1 \\
11.0 \\
17.9 \\
14.3 \\
10.6\end{array}$ & $\begin{array}{r}20.8 \\
40.3 \\
37.6 \\
21.0 \\
13.0 \\
47.7 \\
3.8 \\
8.9 \\
12.8 \\
6.5\end{array}$ \\
\hline Age (years): mean (s.d.) & $49.7(9.8)$ & $51.0(9.9)$ & $51.6(9.9)$ & $52.1(10.0)$ & $51.8(10.0)$ \\
\hline \multicolumn{6}{|c|}{ Self-reported diabetes mellitus ${ }^{b}(\%)$} \\
\hline $\begin{array}{l}\text { No } \\
\text { Yes }\end{array}$ & $\begin{array}{l}19.9 \\
16.4\end{array}$ & $\begin{array}{l}19.9 \\
19.3\end{array}$ & $\begin{array}{l}20.0 \\
20.2\end{array}$ & $\begin{array}{l}20.1 \\
22.0\end{array}$ & $\begin{array}{l}20.2 \\
22.1\end{array}$ \\
\hline \multicolumn{6}{|l|}{ Educational level $^{\mathrm{b}}(\%)$} \\
\hline $\begin{array}{l}\text { None/primary } \\
\text { Technical/professional/secondary } \\
\text { University degree/longer }\end{array}$ & $\begin{array}{l}19.2 \\
22.1 \\
17.8\end{array}$ & $\begin{array}{l}17.4 \\
21.4 \\
21.0\end{array}$ & $\begin{array}{l}17.9 \\
20.4 \\
21.7\end{array}$ & $\begin{array}{l}20.8 \\
18.9 \\
20.7\end{array}$ & $\begin{array}{l}24.7 \\
17.2 \\
18.9\end{array}$ \\
\hline \multicolumn{6}{|l|}{ Smoking $^{\mathbf{b}}(\%)$} \\
\hline $\begin{array}{l}\text { Never } \\
\text { Former } \\
\text { Current }\end{array}$ & $\begin{array}{l}16.0 \\
18.7 \\
30.3\end{array}$ & $\begin{array}{l}19.1 \\
20.8 \\
21.0\end{array}$ & $\begin{array}{l}20.7 \\
21.0 \\
17.4\end{array}$ & $\begin{array}{l}21.9 \\
20.1 \\
15.8\end{array}$ & $\begin{array}{l}22.3 \\
19.5 \\
15.6\end{array}$ \\
\hline \multicolumn{6}{|l|}{ Ethanol intake $\left(\mathrm{g} \mathrm{d}^{-1}\right)^{\mathrm{b}}(\%)$} \\
\hline $\begin{array}{l}\text { Low }^{c} \\
\text { Moderate } \\
\text { High }^{c}\end{array}$ & $\begin{array}{l}19.1 \\
19.0 \\
26.0\end{array}$ & $\begin{array}{l}19.4 \\
20.8 \\
20.4\end{array}$ & $\begin{array}{l}19.5 \\
21.1 \\
19.1\end{array}$ & $\begin{array}{l}20.3 \\
20.3 \\
18.0\end{array}$ & $\begin{array}{l}21.7 \\
18.8 \\
16.4\end{array}$ \\
\hline \multicolumn{6}{|l|}{ Body mass index $\left(\mathrm{kg} \mathrm{m}^{-2}\right)^{b}(\%)$} \\
\hline $\begin{array}{l}\leqslant 25 \\
>25-<30 \\
\geqslant 30\end{array}$ & $\begin{array}{l}21.0 \\
19.1 \\
18.2\end{array}$ & $\begin{array}{l}20.9 \\
19.5 \\
17.9\end{array}$ & $\begin{array}{l}20.6 \\
19.8 \\
18.3\end{array}$ & $\begin{array}{l}19.8 \\
20.1 \\
20.8\end{array}$ & $\begin{array}{l}17.7 \\
21.6 \\
24.8\end{array}$ \\
\hline \multicolumn{6}{|l|}{ Physical activity index ${ }^{b}(\%)$} \\
\hline $\begin{array}{l}\text { Moderately inactive } \\
\text { Moderately active }^{\mathbf{d}}\end{array}$ & $\begin{array}{l}18.8 \\
18.4\end{array}$ & $\begin{array}{l}18.9 \\
19.8\end{array}$ & $\begin{array}{l}19.5 \\
20.9\end{array}$ & $\begin{array}{l}21.2 \\
20.3\end{array}$ & $\begin{array}{l}21.7 \\
20.6\end{array}$ \\
\hline Energy intake (kcal d ${ }^{-1}$ ): mean (s.d.) & $1880.3(652.2)$ & $1994.4(627.2)$ & $2077.2(642.8)$ & $2152.2(656.6)$ & $2320.2(728.2)$ \\
\hline Total (number) & 97361 & 97358 & 97361 & 97359 & 97360 \\
\hline \multicolumn{6}{|c|}{ 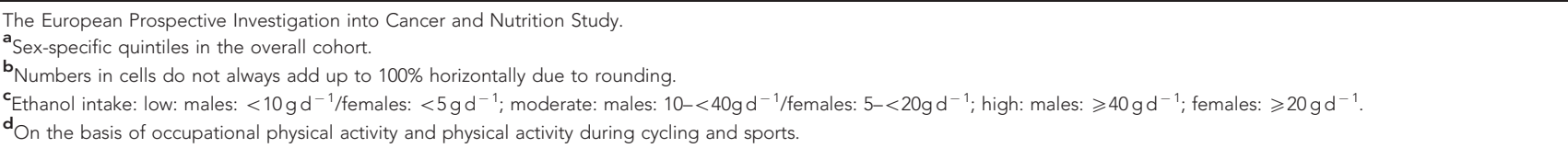 } \\
\hline
\end{tabular}

The role of fruit intake in HCC incidence as investigated in epidemiological studies is inconclusive: an inverse association of fruit intake with HCC risk has been reported mainly from casecontrol studies in northern Italy, but these associations have either considered the combination of fruit and vegetable intake (Braga et al, 1997) or did not reach statistical significance (Talamini et al, 2006). Interestingly, the cohort study by Kurahashi et al (2009) reported an apparent higher risk of HCC with higher fruit intakes, albeit not statistically significant, whereas an a-posteriori fruitbased dietary pattern was not found to be associated with HCC incidence in the Chinese cohort study of Zhang et al (2013). Our analyses did not reveal an association of fruit intake with HCC risk, a finding that was consistent in subgroup and sensitivity analyses. Not surprisingly, when the total intake of fruit and vegetables was considered, an overall association of this combined dietary exposure was not evident due to the null association of fruit with HCC risk.
Several mechanisms could underlie the inverse association between vegetable intake and HCC risk. Vegetable intake has been suggested to be inversely related to chronic liver disease (Cook et al, 2014), or diabetes mellitus (Clifton et al, 2014). In previous studies, however, the inverse association between vegetable and HCC risk was evident in subjects irrespectively of documented chronic liver disease or HBV/HCV positivity status (Yu et al, 1995; Kurahashi et al, 2009). We did not have detailed information overall about chronic liver disease: however, when the first 2 years of follow-up were excluded (thus a fraction of cases with underlying liver disease were most likely also excluded), results were practically unchanged. Of note, our results were adjusted for diabetes and there was no evidence for diabetes-by-vegetable interaction. Moreover, in analyses performed in the nested casecontrol study, adjusting for chronic infection with $\mathrm{HBV} / \mathrm{HCV}$ did not materially affect the point estimates of the association of vegetable and fruit intake with HCC risk, nor was there a 
with serum retinol levels was observed, which complemented the apparent inverse association of vegetable intake with HCC risk found in the same study, whereas in the study by Kurahashi et al (2009) an inverse association between a- and b-carotene and HCC risk was also shown. Another possible pathway for the protective role of vegetables on HCC risk may be through their flavonoid content, which has been suggested by studies in vitro to have antitumour effect in some hepatocarcinoma cell lines (Hwang et al, 2011; Mansoor et al, 2011). In a previous EPIC study, the association of dietary intakes of flavonoids with HCC risk was investigated (Zamora-Ros et al, 2013), and inverse associations with total flavonoid intake (in specific, with flavanol intake) were observed. In a recent EPIC study, Fedirko et al (2013) observed an inverse association between dietary fibre from vegetables and HCC risk which, again, may at least partly explain our results. Interestingly, in the study of Fedirko et al (2013) fibre from fruit was not associated with HCC risk. We were not able to investigate the mediating effect of antioxidant intakes or total antioxidant capacity on the estimated associations, because this information is not available in our data set.

Regarding fruit, in the case-control studies in which inverse associations with HCC risk were observed, these were attributed mainly to the antioxidant properties of fruit polyphenols. Given the inconclusive collective evidence in the literature, further studies are needed to affirm any role of fruit on HCC risk before exploring any underlying mechanisms.

Strengths of our study are its prospective design, its multicentre coverage allowing investigation of a variable range of fruit and vegetable intakes across European countries, the use of validated questionnaires and common $24 \mathrm{HRs}$, the relatively long follow-up, the common identification criteria of incident HCC and the available information about potential confounders.

A limitation of our study is the unavoidable modest number of HCC outcomes, owing to the low incidence of the disease in most European countries. Errors in reporting vegetable and fruit consumptions cannot be ruled out, but this is more likely to result in random misclassification of the dietary exposures, thus resulting in underestimation of true associations. Heterogeneity in the estimated associations may exist across countries, but we tried to account for this by stratifying for centre and calibrating our estimates using the $24 \mathrm{~h}$ recall data. Bias in the estimated associations could have been introduced if cases had modified their vegetable/fruit consumption during the prediagnostic period of their disease, but excluding cases diagnosed in the first 2 years of follow-up did not alter the results. We did not further inspect whether the apparent association between vegetable intake and HCC risk was driven by a specific subgroup of vegetables with similar features (e.g., cruciferous vegetables) because (a) such analysis would be possibly underpowered due to the small number of HCC cases and the small underlying magnitude of the hypothesised associations and (b) there is no current evidence to favour one or another subgroup of vegetables as more/less responsible for the apparent association.

In conclusion, in a large prospective study across European countries, we observed a lower HCC risk associated with higher vegetable but not fruit intakes. Further epidemiological and mechanistic studies should better clarify the pathways underlying this association. There was no evidence of heterogeneity of the estimated associations across strata defined by established HCC risk factors. Given that vegetables are practically universally accessible, and that the prognosis of HCC is poor, our results, taken together with current evidence, may prompt for dietary intervention studies on HCC incidence among those who are at high risk for the disease.

\section{ACKNOWLEDGEMENTS}

The coordination of EPIC is financially supported by the European Commission (DG-SANCO) and the International Agency for Research on Cancer. This work was in part supported by the French National Cancer Institute (L'Institut National du Cancer) (grant number 2009-139; PI: M Jenab).The national cohorts are supported by: Danish Cancer Society (Denmark); Ligue Contre le Cancer, Institut Gustave Roussy, Mutuelle Générale de l'Education Nationale, Institut National de la Santé et de la Recherche Médicale (INSERM) (France); German Cancer Aid, German Cancer Research Center (DKFZ) and Federal Ministry of Education and Research (BMBF, Germany); Stavros Niarchos Foundation and Hellenic Health Foundation (Greece); Italian Association for Research on Cancer (AIRC), National Research Council, HuGeF Foundation, Compagnia di San Paolo, Sicilian Government, AIRE ONLUS Ragusa (Italy); Dutch Ministry of Public Health, Welfare and Sports (VWS), Netherlands Cancer Registry (NKR), LK Research Funds, Dutch Prevention Funds, Dutch ZON (Zorg Onderzoek Nederland), World Cancer Research Fund and Statistics Netherlands (The Netherlands); ERC-2009-AdG 232997 and Nordforsk, Nordic Centre of Excellence programme on Food, Nutrition and Health, Norwegian Research Council (Norway); Health Research Fund (FIS), Regional Governments of Andalucía, Asturias, Basque Country, Murcia (no. 6236) and Navarra, ISCIII RETIC (RD06/ 0020) (Spain); Swedish Cancer Society, Swedish Scientific Council and Regional Government of Skåne and Västerbotten (Sweden); Cancer Research UK, Medical Research Council (UK). We thank Ms Carine Biessy for her efforts and work in conducting part of the statistical analyses for this project and B Hemon for his assistance in database preparation. We also thank Dr E Trepo (Labo Republique, Lyon) for her contribution to the project and biomarker analyses in the nested case-control component.

\section{CONFLICT OF INTEREST}

The authors declare no conflict of interest.

\section{DISCLAIMER}

None of the funding sources had any role in the design and conduct of the study; collection, management, analysis and interpretation of the data; preparation, review or approval of the manuscript, and decision to submit the manuscript for publication.

\section{AUTHOR CONTRIBUTIONS}

All named authors have read the manuscript, have agreed to the submission and have participated in the study to a sufficient extent to be named as authors.

\section{REFERENCES}

Agudo A, Slimani N, Ocké MC, Naska A, Miller AB, Kroke A, Bamia C, Karalis D, Vineis P, Palli D, Bueno-de-Mesquita HB, Peeters PH, Engeset D, Hjartåker A, Navarro C, Martínez Garcia C, Wallström P, Zhang JX, Welch AA, Spencer E, Stripp C, Overvad K, Clavel-Chapelon F, Casagrande C, Riboli E (2002) Consumption of vegetables, fruit and other plant foods in the European Prospective Investigation into Cancer and Nutrition (EPIC) cohorts from 10 European countries. Public Health Nutr 5: $1179-1196$. 
Braga C, La Vecchia C, Negri E, Franceschi S (1997) Attributable risks for hepatocellular carcinoma in northern Italy. Eur J Cancer 33: 629-634.

Chuang SC, La Vecchia C, Boffetta P (2009) Liver cancer: descriptive epidemiology and risk factors other than HBV and HCV infection. Cancer Lett 286: 9-14.

Clifton PM, Petersen KS, Blanch N, Keogh JB (2014) How do fruit and vegetables prevent heart disease and type 2 diabetes? Curr Opin Lipidol 25: $155-156$.

Cook LT, O’Reilly GA, Goran MI, Weigensberg MJ, Spruijt-Metz D, Davis JN (2014) Vegetable consumption is linked to decreased visceral and liver fat and improved insulin resistance in overweight Latino youth. J Acad Nutr Diet 114: 1776-1783.

Fedirko V, Lukanova A, Bamia C, Trichopolou A, Trepo E, Nöthlings U, Schlesinger S, Aleksandrova K, Boffetta P, Tjønneland A, Johnsen NF, Overvad K, Fagherazzi G, Racine A, Boutron-Ruault MC, Grote V, Kaaks R, Boeing H, Naska A, Adarakis G, Valanou E, Palli D, Sieri S, Tumino R, Vineis P, Panico S, Bueno-de-Mesquita HB, Siersema PD, Peeters PH, Weiderpass E, Skeie G, Engeset D, Quirós JR, Zamora-Ros R, Sánchez MJ, Amiano P, Huerta JM, Barricarte A, Johansen D, Lindkvist B, Sund M, Werner M, Crowe F, Khaw KT, Ferrari P, Romieu I, Chuang SC, Riboli E, Jenab M (2013) Glycemic index, glycemic load, dietary carbohydrate, and dietary fibre intake and risk of liver and biliary tract cancers in Western Europeans. Ann Oncol 24: 543-553.

Ferlay J, Soerjomataram I, Ervik M, Dikshit R, Eser S, Mathers C, Rebelo M, Parkin DM, Forman D, Bray F (2013) GLOBOCAN 2012 v1.0, Cancer Incidence and Mortality Worldwide: IARC CancerBase No. 11. International Agency for Research on Cancer: Lyon, France (http:// globocan.iarc.fr).

Ferrari P, Kaaks R, Fahey MT, Slimani N, Day NE, Pera G, Boshuizen HC, Roddam A, Boeing H, Nagel G, Thiebaut A, Orfanos P, Krogh V, Braaten T, Riboli E (2004) Within- and between-cohort variation in measured macronutrient intakes, taking account of measurement errors, in the European prospective investigation into cancer and nutrition study. Am J Epidemiol 160: 814-822.

Hwang JT, Park OJ, Lee YK, Sung MJ, Hur HJ, Kim MS, Ha JH, Kwon DY (2011) Anti-tumor effect of luteolin is accompanied by AMP-activated protein kinase and nuclear factor-kappaB modulation in HepG2 hepatocarcinoma cells. Int J Mol Med 28: 25-31.

International Agency for Research on Cancer (1988) IARC monographs on the evaluation of carcinogenic risks to humans. In: Alcohol Drinking vol. 44IARC: Lyon, France.

International Agency for Research on Cancer (2002) Aflatoxins. In: Traditional Herbal Medicines, Some Mycotoxins, Naphthalene and Styrene. IARC Monographs on the Evaluation of Carcinogenic Risks to Humans vol. 82IARC: Lyon, France.

Kanazir M, Boricic I, Delic D, Tepavcevic DK, Knezevic A, Jovanovic T, Pekmezovic T (2010) Risk factors for hepatocellular carcinoma: a case-control study in Belgrade (Serbia). Tumori 96: 911-917.

Kuper H, Tzonou A, Lagiou P, Mucci LA, Trichopoulos D, Stuver SO, Trichopoulou A (2000) Diet and hepatocellular carcinoma: a case-control study in Greece. Nutr Cancer 2000 38: 6-12.

Kurahashi N, Inoue M, Iwasaki M, Tanaka Y, Mizokami M, Tsuqane S. JPHC Study Group (2009) Vegetable, fruit and antioxidant nutrient consumption and subsequent risk of hepatocellular carcinoma: a prospective cohort study in Japan. Br J Cancer 100: 181-184.

Kurozawa Y, Ogimoto I, Shibata A, Nose T, Yoshimura T, Suzuki H, Sakata R, Fujita Y, Ichikawa S, Iwai N, Fukuda K, Tamakoshi A (2004) Dietary habits and risk of death due to hepatocellular carcinoma in a large scale cohort study in Japan. Univariate analysis of JACC study data. Kurume Med J 51: 141-149.

La Vecchia C, Negri E, Decarli A, D’Avanzo B, Franceschi S (1988) Risk factors for hepatocellular carcinoma in northern Italy. Int J Cancer 42: 872-876.

Mansoor TA, Ramalho RM, Luo X, Ramahalte C, Rodrigues CM, Ferreira M) (2011) Isoflavones as apoptosis inducers in human hepatoma HuH-7 cells. Phytother Res 25: 1819-1824.

Margetts BM, Pietinen P, Riboli E (1997) EPIC European Prospective Investigation into Cancer and Nutrition. Validation studies on dietary assessment methods. Int J Epidemiol 26(Suppl 1): 1-189.

Moreno FS, S-Wu T, Naves MM, Silveira ER, Oloris SC, da Costa MA, Dagli ML, Ong TP (2002) Inhibitory effects of b-carotene and vitamin a during the progression phase of hepatocarcinogenesis involve inhibition of cell proliferation but not alterations in DNA methylation. Nutr Cancer 44: 80-88.
Negri E, La Vecchia C, Franceschi S, D’Avanzo B, Parazzini F (1991) Vegetable and fruit consumption and cancer risk. Int J Cancer 48: 350-354.

Pham T-M, Fujino Y, Ide R, Kubo T, Shirane K, Tokui N, Mizoue T, Ogimoto I, Matsuda S, Yoshimura T (2006) Prospective study of vegetable consumption and liver cancer in Japan. Int. J. Cancer 119: 2408-2411.

Riboli E, Hunt KJ, Slimani N, Ferrari P, Norat T, Fahey M, Charrondière UR, Hémon B, Casagrande C, Vignat J, Overvad K, Tjønneland A, Clavel-Chapelon F, Thiébaut A, Wahrendorf J, Boeing H, Trichopoulos D, Trichopoulou A, Vineis P, Palli D, Bueno-De-Mesquita HB, Peeters PH, Lund E, Engeset D, González CA, Barricarte A, Berglund G, Hallmans G, Day NE, Key TJ, Kaaks R, Saracci R (2002) European Prospective Investigation into Cancer and Nutrition (EPIC): study populations and data collection. Public Health Nutr 5: 1113-1124.

Rosner B, Gore R (2001) Measurement error correction in nutritional epidemiology based on individual foods, with application to the relation of diet to breast cancer. Am J Epidemiol 154: 827-835.

Sano T, Kagawa M, Okuno M, Ishibashi N, Hashimoto M, Yamamoto M, Suzuki R, Kohno H, Matsushima-Nishiwaki R, Takano Y, Tsurumi H, Kojima S, Friedman SL, Moriwaki H, Tanaka T (2005) Prevention of rat hepatocarcinogenesis by acyclic retinoid is accompanied by reduction in emergence of both TGF-a-expressing oval-like cells and activated hepatic stellate cells. Nutr Cancer 51: 197-206.

Sauvaget C, Nagano J, Hayashi M, Spencer E, Shimizu Y, Allen N (2003) Vegetables and fruit intake and cancer mortality in the Hiroshima/ Nagasaki Life Span Study. Br J Cancer 88: 689-694.

Schlesinger S, Aleksandrova K, Pischon T, Fedirko V, Jenab M, Trepo E, Boffetta P, Dahm CC, Overvad K, Tjønneland A, Halkjær J, Fagherazzi G, Boutron-Ruault MC, Carbonnel F, Kaaks R, Lukanova A, Boeing H, Trichopoulou A, Bamia C, Lagiou P, Palli D, Grioni S, Panico S, Tumino R, Vineis P, Bueno-de-Mesquita HB, van den Berg S, Peeters PH, Braaten T, Weiderpass E, Quirós JR, Travier N, Sánchez MJ, Navarro C, Barricarte A, Dorronsoro M, Lindkvist B, Regner S, Werner M, Sund M, Khaw KT, Wareham N, Travis RC, Norat T, Wark PA, Riboli E, Nöthlings U (2013) Abdominal obesity, weight gain during adulthood and risk of liver and biliary tract cancer in a European cohort. Int J Cancer 132: 645-657.

Slimani N, Fahey M, Welch AA, Wirfält E, Stripp C, Bergström E, Linseisen J, Schulze MB, Bamia C, Chloptsios Y, Veglia F, Panico S, Bueno-de-Mesquita HB, Ocké MC, Brustad M, Lund E, González CA, Barcos A, Berglund G, Winkvist A, Mulligan A, Appleby P, Overvad K, Tjønneland A, Clavel-Chapelon F, Kesse E, Ferrari P, Van Staveren WA, Riboli E (2002) Diversity of dietary patterns observed in the European Prospective Investigation into Cancer and Nutrition (EPIC) project. Public Health Nutr 5: 1311-1328.

Slimani N, Kaaks R, Ferrari P, Casagrande C, Clavel-Chapelon F, Lotze G, Kroke A, Trichopoulos D, Trichopoulou A, Lauria C, Bellegotti M, Ocké MC, Peeters PH, Engeset D, Lund E, Agudo A, Larrañaga N, Mattisson I, Andren C, Johansson I, Davey G, Welch AA, Overvad K, Tjønneland A, Van Staveren WA, Saracci R, Riboli E (2002) European prospective investigation into cancer and nutrition (EPIC) calibration study: rationale, design and population characteristics. Public Health Nutr 5: 1125-1145.

Slimani N, Deharveng G, Unwin I, Southgate DA, Vignat J, Skeie G, Salvini S, Parpinel M, Møller A, Ireland J, Becker W, Farran A, Westenbrink S, Vasilopoulou E, Unwin J, Borgejordet A, Rohrmann S, Church S, Gnagnarella P, Casagrande C, van Bakel M, Niravong M, Boutron-Ruault MC, Stripp C, Tjønneland A, Trichopoulou A, Georga K, Nilsson S, Mattisson I, Ray J, Boeing H, Ocké M, Peeters PH, Jakszyn P, Amiano P, Engeset D, Lund E, de Magistris MS, Sacerdote C, Welch A, Bingham S, Subar AF, Riboli E (2007) The EPIC nutrient database project (ENDB): a first attempt to standardize nutrient databases across the 10 European countries participating in the EPIC study. Eur J Clin Nutr 61: 1037-1056.

Soerjomataram I, Oomen D, Lemmens V, Oenema A, Benetou V, Trichopoulou A, Coebergh JW, Barendregt J, de Vries E (2010) Increased consumption of fruit and vegetables and future cancer incidence in selected European countries. Eur J Cancer 46: 2563-2580.

Sporn MB, Roberts AB (1983) Role of retinoids in differentiation and carcinogenesis. Cancer Res 43: 3034-3040.

Talamini R, Polesel J, Montella M, Dal Maso L, Crispo A, Tommasi LG, Izzo F, Crovatto M, La Vecchia C, Franceschi S (2006) Food groups and risk of hepatocellular carcinoma: a multicenter case-control study in Italy. Int J Cancer 119: 2916-2921.

Trichopoulos D, Bamia C, Lagiou P, Fedirko V, Trepo E, Jenab M, Pischon T, Nöthlings U, Overved K, Tjønneland A, Outzen M, Clavel-Chapelon F, 
Kaaks R, Lukanova A, Boeing H, Aleksandrova K, Benetou V, Zylis D, Palli D, Pala V, Panico S, Tumino R, Sacerdote C, Bueno-De-Mesquita HB, Van Kranen HJ, Peeters PH, Lund E, Quirós JR, González CA, Sanchez Perez MJ, Navarro C, Dorronsoro M, Barricarte A, Lindkvist B, Regnér S, Werner M, Hallmans G, Khaw KT, Wareham N, Key T, Romieu I, Chuang SC, Murphy N, Boffetta P, Trichopoulou A, Riboli E (2011) Hepatocellular carcinoma risk factors and disease burden in a European cohort: a nested case-control study. J Natl Cancer Inst 103: 1686-1695.

Vainio H, Weiderpass E (2006) Fruit and vegetables in cancer prevention. Nutr Cancer 54: 111-142.

World Cancer Research Fund/American Institute for Cancer Research (2007) Food, Nutrition, Physical Activity, and the Prevention of Cancer: a Global PerspectiveAICR: Washington DC, USA.

Yu MW, Hsieh HH, Pan WH, Yang CS, CHen CJ (1995) Vegetable consumption, serum retinol level, and risk of hepatocellular carcinoma. Cancer Res 55: 1301-1305.

Zamora-Ros R, Fedirko V, Trichopoulou A, González CA, Bamia C, Trepo E, Nöthlings U, Duarte-Salles T, Serafini M, Bredsdorff L, Overvad K, Tjønneland A, Halkjaer J, Fagherazzi G, Perquier F, Boutron-Ruault MC,
Katzke V, Lukanova A, Floegel A, Boeing H, Lagiou P, Trichopoulos D, Saieva C, Agnoli C, Mattiello A, Tumino R, Sacerdote C, Bueno-de-Mesquita HB, Peeters PH, Weiderpass E, Engeset D, Skeie G, Argüelles MV, Molina-Montes E, Dorronsoro M, Tormo MJ, Ardanaz E, Ericson U, Sonestedt E, Sund M, Landberg R, Khaw KT, Wareham NJ, Crowe FL, Riboli E, Jenab M (2013) Dietary flavonoid, lignan and antioxidant capacity and risk of hepatocellular carcinoma in the European prospective investigation into cancer and nutrition study. Int J Cancer 133: 2429-2443.

Zhang W, Xiang Y-B, Li H-L, Yang G, Cai H, Ji B-T, Gao Y-T, Zheng W, Shu X-O (2013) Vegetable-based dietary pattern and liver cancer risk: results from the Shanghai Women's and Men's Health Studies. Cancer Sci 104: $1353-1361$.

This work is published under the standard license to publish agreement. After 12 months the work will become freely available and the license terms will switch to a Creative Commons AttributionNonCommercial-Share Alike 4.0 Unported License. 